\title{
Failures, Mistakes and Shortcomings of My Stroke Trials
}

\author{
Hans-Christoph Diener \\ Department of Neurology, University Hospital Essen, Essen, Germany
}

\section{Introduction}

Treatment and prevention of stroke depend on the results of well-planned and executed randomized trials. Trial methodology has developed over the last 30 years, and at present we have very sophisticated ways to perform randomized trials. I started to participate in my first randomized trial in 1989 after finishing my residency in neurology. Until $2013 \mathrm{I}$ had participated in $>100$ trials in the acute treatment and prevention of stroke. Over the years I became aware of many shortcomings in the design, execution and interpretation of clinical trials in which I participated.

In this paper I would like to give a few examples and describe how modern trial design helps to avoid these mistakes in the future. Quoting Winston Churchill: 'All men make mistakes, but only wise men learn from their mistakes' (table 1).

\section{Asymptomatic Carotid Stenosis}

In 1989 carotid surgery for symptomatic high-degree stenosis of the internal carotid artery was well established, and 2 randomized trials (NASCET and ECST) were ongoing $[1,2]$ comparing carotid endarterectomy and med- ical treatment. The role of carotid surgery in asymptomatic carotid stenosis was unclear. The prospective study by Hennerici et al. [3] indicated that the stroke risk was relatively small. A group of vascular surgeons, neurologists and clinical trial experts therefore applied for a grant from the German Ministry of Science and Technology to perform a randomized trial comparing carotid surgery with best medical treatment in patients with asymptomatic carotid stenosis. After the grant had been approved, we called a meeting with the surgical centers in Germany from whom we knew that they had enough expertise in carotid surgery. Unfortunately the participating vascular surgeons thought that withholding surgery from patients with severe carotid stenosis and patients with bilateral disease would be unethical. Therefore the trial only randomized patients with unilateral moderate carotid stenosis. In addition the trial was underpowered and predictably failed to show a difference between surgical and medical treatment [4].

The lessons to be learned are as follows:

(1) A good study acronym (CASANOVA) does not replace a proper study design

(2) Sometimes it is better not to start a trial than to accept compromises which decrease the likelihood of achieving positive results

\section{KARGER}

E-Mail karger@karger.com

www.karger.com/ced (c) 2013 S. Karger AG, Basel

$1015-9770 / 13 / 0364-0250 \$ 38.00 / 0$
Prof. Hans-Christoph Diener

Department of Neurology, University Duisburg-Essen

Hufelandstr. 55

DE-45122 Essen (Germany)

E-Mail h.diener@uni-essen.de 
Table 1. Famous quotes on mistakes

- Experience is the name everyone gives to their mistakes. Oscar Wilde

- Nowadays most people die of a sort of creeping common sense, and discover when it is too late that the only things one never regrets are one's mistakes. Oscar Wilde

- Mistakes, obviously, show us what needs improving. Without mistakes, how would we know what we had to work on? Peter McWilliams

- Creativity is allowing yourself to make mistakes. Art is knowing which ones to keep. Scott Adams

- Success seems to be connected with action. Successful people keep moving. They make mistakes, but they don't quit. Conrad Hilton

- Anyone who has never made a mistake has never tried anything new. Albert Einstein

- What do you first do when you learn to swim? You make mistakes, do you not? And what happens? You make other mistakes, and when you have made all the mistakes you possibly can without drowning - and some of them many times over what do you find? That you can swim? Well - life is just the same as learning to swim! Do not be afraid of making mistakes, for there is no other way of learning how to live! Alfred Adler

- I think we all wish we could erase some dark times in our lives. But all of life's experiences, bad and good, make you who you are. Erasing any of life's experiences would be a great mistake. Luis Miguel

- All men make mistakes, but only wise men learn from their mistakes. Winston Churchill

- Take chances, make mistakes. That's how you grow. Pain nourishes your courage. You have to fail in order to practice being brave. Mary Tyler Moore

- There are no mistakes. The events we bring upon ourselves, no matter how unpleasant, are necessary in order to learn what we need to learn; whatever steps we take, they're necessary to reach the places we've chosen to go. Richard Bach

- The only real mistake is the one from which we learn nothing. John Powell

- If you have made mistakes, there is always another chance for you. You may have a fresh start any moment you choose, for this thing we call 'failure' is not the falling down, but the staying down. Mary Pickford

- The only man who never makes a mistake is the man who never does anything. Theodore Roosevelt

- Never interrupt your enemy when he is making a mistake. Napoleon Bonaparte

- A mistake is to commit a misunderstanding. Bob Dylan

- Even a mistake may turn out to be the one thing necessary to a worthwhile achievement. Henry Ford

- You just keep pushing. You just keep pushing. I made every mistake that could be made. But I just kept pushing. René Descartes

- Nobody made a greater mistake than he who did nothing because he could do only a little. Edmund Burke

- A well-adjusted person is one who makes the same mistake twice without getting nervous. Alexander Hamilton

From http://www.psychologytoday.com/blog/here-there-andeverywhere/201109/30-quotes-making-mistakes.

Failures, Mistakes and Shortcomings of My Stroke Trials

\section{Neuroprotective Therapy}

Cerebral ischemia triggers excessive presynaptic release of the excitatory neurotransmitter glutamate and the energy uncoupling prevents active removal of glutamate from the synaptic cleft. The excess of glutamate overstimulates postsynaptic receptors such as the Nmethyl-D-aspartate (NMDA) receptor, thereby opening the associated ion channel and allowing sodium and calcium ions to enter the cell whilst potassium flows outwards. The calcium influx activates intracellular proteases and initiates a cascade of further energy consuming and ultimately lethal processes. Drugs were developed for most of the assumed mechanisms in cerebral focal ischemia and tested successfully in animal experiments of transient or permanent cerebral ischemia. Initially only experiments in healthy young rats were performed. The Stroke Therapy Academic Industry Roundtable issued a number of recommendations how to improve animal experiments including a randomized blinded design, use of placebo and experiments in older rats with vascular diseases or even primates [5-10]. Despite more than 1,000 papers reporting positive results in animal experiments, until today none of the $>150$ randomized trials in human stroke investigating neuroprotective therapy has been successful.

\section{The ASSIST Trial}

Selfotel is a selective NMDA antagonist. Selfotel was effective in animal models of stroke, when young rats without concomitant vascular risk factors were examined. Dose-finding studies did not reveal major problems in terms of adverse events [11]. The phase III trial planned to recruit 1,000 patients with acute ischemic stroke. The trial was terminated prematurely by the data safety monitoring board when 3 -month data from 476 patients were available [12]. Mortality at this point in time was $13 \%$ with selfotel and $5 \%$ with placebo.

The lessons learned from ASSIST were as follows:

(1) The study in humans was started with very little data from animal experiments

(2) The results in animals were not gained in placebocontrolled trials and the data were not replicated by an independent laboratory

(3) The study started with not enough safety data in elderly patients with vascular risk factors or vascular diseases 
(4) Serious adverse events like death were not reported immediately, which caused a delay in terminating the study. Modern GCP guidelines require communication of serious adverse events within $24 \mathrm{~h}$

\section{Lubeluzole}

Lubeluzole is a benzothiazole derivative that has been shown experimentally to preserve neurological function and reduce infarct volume in animal models of focal brain ischemia $[13,14]$. The neuroprotective activity of lubeluzole is related to its ability to alter the biochemical cascade that leads to irreversible neural damage in the penumbra, by preventing an increase in extracellular glutamate and normalizing neuronal excitability in the peri-infarct region [15]. Experiments with cultured embryonic hippocampal neurons further indicated that the drug inhibits glutamate-induced nitric oxide-related neurotoxicity [16].

Lubeluzole was investigated in 2 phase III trials [17, 18]. The dose was smaller than anticipated from the results of animal experiments because higher plasma levels in humans resulted in QT time prolongation. The time window for inclusion was $8 \mathrm{~h}$, and the primary end point was the score of the Barthel index at 12 weeks. The core analysis group was defined by a time window of $6 \mathrm{~h}$ and age $<75$ years. The trials were negative for the primary and secondary end points.

Lessons learned from the lubeluzole program:

(1) Lubeluzole was the first neuroprotective substance investigated in a proper phase II program

(2) Due to anticipated QT time prolongations with higher doses of lubeluzole in humans, the drug was probably underdosed. A post hoc analysis after the trial program had been terminated showed a significant relationship between plasma levels and efficacy [unpubl. data]

(3) The trial also showed that patients with very severe strokes and elderly patients have a poor prognosis independent of treatment assignment [19]

(4) The Barthel index is a poor outcome parameter. The index has a U-shaped distribution and therefore a poor discrimination threshold [20]

\section{Gavestinel}

Gavestinel (GV150526) is a potent and selective antagonist at the glycine site of the NMDA receptor. It reduces infarct size in rats by slightly more than $50 \%$ when administered intravenously within $6 \mathrm{~h}$ after the onset of middle cerebral artery occlusion [21]. The compound was well tolerated by volunteers and by stroke patients [22]. Because gavestinel does not affect platelet or coagulation function, and has beneficial effects in an animal model of traumatic intracranial hemorrhage [unpubl. data], the drug has been thought suitable for widespread use without prior neuroimaging. Phase II studies with gavestinel were unsuited to assess outcome trends because there was imbalance in prognostic variables between groups, the time window to treatment of $12 \mathrm{~h}$ was rather long, and the follow-up period of 1 month was too short [23]. However, the drug was very well tolerated. Two phase III placebo-controlled trials with gavestinel were performed in the USA $(\mathrm{n}=1,367)$ and the rest of the world $(n=1,804)[24,25]$. The inclusion time was $6 \mathrm{~h}$ and patients were treated for 3 days. Patients with ischemic as well as hemorrhagic strokes were included. Patients were stratified according to age and stroke severity. Limb weakness in the National Institutes of Health Stroke Scale was required. Both studies failed to show a difference between gavestinel and placebo.

Lesions to be learned from the gavestinel program:

(1) Patients with ischemia and cerebral hemorrhage should not be randomized in the same trial

(2) The absence of central side effects could indicate that a neuroprotective substance does not cross the bloodbrain barrier

\section{The SAINT Study Programme}

NXY-059 was a free-radical-trapping agent, which had undergone the most extensive preclinical development in experimental stroke. The substance was effective in young and old rats as well as in primates and showed efficacy in animal experiments both for transient and permanent middle cerebral artery occlusion [26, 27]. The phase III program had a 6-hour inclusion time window and allowed patients receiving thrombolysis with recombinant tissue plasminogen activator to be randomized. The primary end point was the distribution of the modified Rankin scale. The first trial randomized 1,722 patients and was positive for the primary end point but failed to achieve superiority versus placebo for a number of secondary end points [28]. The second trial with 3,306 patients and a similar study design was neutral as was the pooled analysis of the 2 phase III studies [29]. The drug was well tolerated and showed no difference in adverse events between active drug and placebo. 
Lessons to be learned from SAINT:

(1) One positive placebo-controlled trial does not prove that a neuroprotective drug is effective in the treatment of ischemic stroke

(2) Absence of side effects of a neuroprotective drug might indicate that the drug does not reach the target area

\section{New Antithrombotics: Abciximab in Acute Ischemic Stroke}

Abciximab is a platelet glycoprotein IIb/IIIa receptor antagonist and was effective in patients undergoing percutaneous coronary interventions [30] and those with unstable angina [31]. The hypothesis was that this drug would be at least as effective as recombinant tissue plasminogen activator in ischemic stroke and should have a longer time window. We conducted a phase II dose-finding trial in 54 patients on the active drug and 20 on placebo [32]. The drug seemed to be safe and showed a trend towards an improved outcome.

An international, randomized, placebo-controlled, double-blind phase III trial tested the intravenous administration of abciximab in acute ischemic stroke with stratification for time since onset and stroke severity [33]. The planned enrolment was 1,800 patients. The inclusion time was $6 \mathrm{~h}$. The primary efficacy measure was the dichotomous modified Rankin scale score at 3 months as adjusted to the baseline severity of stroke among subjects in the primary cohort. The primary safety outcome was the rate of symptomatic or fatal intracranial hemorrhage that occurred within 5 days of stroke. The trial was terminated prematurely after 808 patients in all cohorts had been enrolled by recommendation of an independent safety and efficacy monitoring board due to an unfavorable benefit-risk profile with an increase in cerebral bleeding complications. At 3 months, $33 \%$ of patients assigned to placebo $(72 / 218)$ and $32 \%$ of patients assigned to abciximab $(71 / 221 ; \mathrm{p}=0.944)$ in the primary cohort were judged to have a favorable response to treatment.

Lessons to be learned from the AbEST trials:

(1) Small phase II trials with antithrombotic therapy in acute ischemic stroke will not be predictive of safety in a larger trial

(2) More potent antithrombotic therapy will lead to more intracranial bleeds and offset any potential beneficial effect

Failures, Mistakes and Shortcomings of My Stroke Trials

\section{Secondary Prevention of Ischemic Stroke}

Patients who suffered a transient ischemic attack or ischemic stroke have a high risk of recurrence. In patients with platelet-rich thrombi originating from atherosclerotic plaques, secondary prevention is performed by antiplatelet therapy. Patients with a cardiac source of embolism are anticoagulated. Most placebo-controlled trials until 1990 used aspirin. The majority of the trials missed the primary end point [34], and therefore aspirin was not approved for the secondary prevention of stroke.

\section{The Combination of Aspirin and Dipyridamole}

The combination of aspirin and dipyridamole was superior to placebo in secondary stroke prevention in the first European Stroke Prevention trial [35]. The Second European Stroke Prevention (ESPS-2) study included 6,602 patients to receive aspirin monotherapy (25 $\mathrm{mg}$ b.i.d.), extended-release dipyridamole (200 $\mathrm{mg}$ b.i.d.), the combination of aspirin and extended-release dipyridamole, or placebo for a mean follow-up of 2 years [36]. Aspirin/dipyridamole significantly reduced the primary end point stroke compared to aspirin monotherapy (relative risk reduction, RRR, 23\%, 95\% confidence interval, CI, $0.65-0.97$ ) and to placebo (RRR 37\%, 95\% CI 0.48-0.73). Major bleeding complications were seen more frequently with aspirin and the combination aspirin and dipyridamole, whereas dipyridamole monotherapy had a similar bleeding rate compared with placebo. Cardiac events occurred in a similar frequency in the groups treated with dipyridamole compared to that treated with aspirin [37]. This was the first large-scale trial which showed that lowdose aspirin is effective in secondary stroke prevention leading to the approval of aspirin for this indication. The original paper from ESPS-2 was submitted to The Lancet but was rejected. One reviewer claimed that it was unethical to use placebo in such a trial, despite the fact that aspirin had not shown efficacy in earlier trials. Another point of critique was the choice of the primary end point which was stroke and not the combined end point of nonfatal stroke, nonfatal myocardial infarction and vascular death. Our power calculation when we started the trial indicated based on earlier trials that antiplatelet therapy would not decrease mortality, and therefore including vascular death would dilute the trial.

Dipyridamole can induce headache in the first days of intake. This adverse event resulted in a considerable number of early dropouts in ESPS-2. Unfortunately we had no

Cerebrovasc Dis 2013;36:250-256 
strategy in place how to handle this problem. Later we learned that a slow titration of dipyridamole can avoid this problem [38]. Another unpleasant surprise was the fact that our monitors detected one center in the Netherlands in which 446 patients had been falsified. ESPS- 2 was one of the first randomized trials with systematic monitoring. Later it turned out that the same investigator had falsified data in 12 earlier trials on stroke and headache. ESPS-2 was heavily attacked because of the faked patients. Our team, however, was the first which identified our criminal colleague. As a consequence he lost his medical license.

Lessons learned from ESPS-2:

(1) Object if a good manuscript is rejected by a major journal

(2) Anticipate adverse events and implement a strategy to deal with them

(3) Monitoring is of the utmost importance to avoid scientific misconduct

\section{Clopidogrel}

Clopidogrel is a thienopyridine derivate and was investigated for the prevention of stroke, myocardial infarction and vascular death in the CAPRIE trial [39]. CAPRIE randomized 19,185 patients with recent ischemic stroke, myocardial infarction or symptomatic peripheral arterial disease to clopidogrel $75 \mathrm{mg}$ or aspirin $325 \mathrm{mg}$. The trial showed a modest RRR of $8.7 \%$ (95\% CI 0.3-16.5) in favor of clopidogrel. In subgroup analyses only patients with peripheral arterial disease showed a clear benefit for clopidogrel over aspirin. This created a fierce scientific debate. Many reimbursement bodies in Europe refused to pay for clopidogrel for secondary stroke prevention [40]. Scientists argued that the overall result of the trial should be considered since subgroup analyses were introduced later.

Lessons learned from CAPRIE:

(1) It is dangerous to mix 3 different patient populations into one trial

(2) Too many post hoc analyses driven by marketing interests might compromise the study

(3) The poor number needed to treat was never properly communicated

\section{The MATCH Trial}

In cardiology the combination of aspirin plus clopidogrel was superior to monotherapy to prevent vascular events in patients with acute coronary syndromes [41] or undergoing percutaneous coronary interventions [42]. The combination, however, had a higher rate of major bleeding complications. We embarked on the MATCH trial in which we compared clopidogrel monotherapy with the combination of aspirin plus clopidogrel in 7,599 high-risk patients with recent ischemic stroke or transient ischemic attack. The trial showed a $6.4 \% \mathrm{RRR}$ for the combined vascular end point and hospitalization which was statistically not significant [43]. We observed a significant increase in life-threatening and major bleeds with combination therapy. MATCH included $52 \%$ of patients with small vessel disease. Whether this population benefits from antiplatelet therapy at all is not clear. In a study which included only patients with lacunar strokes, clopidogrel plus aspirin was not superior to aspirin monotherapy and again showed a higher bleeding risk [44].

Lessons learned from MATCH:

(1) A trial with a mean follow-up of 18 months is too short

(2) An enriched high-risk population might lead to bias

(3) MATCH included a high percentage of patients with diabetes. Patients with diabetes might respond differently to antiplatelet therapy compared to patients with normal glucose metabolism

(4) Patients with small vessel disease might not benefit from antiplatelet therapy

(5) The study should have compared combination therapy with aspirin and not clopidogrel

(6) More potent antiplatelet therapy will lead to an increase in bleeding complications

\section{The PRoFESS Trial}

Clopidogrel was marginally superior to aspirin in the CAPRIE trial [39] and aspirin plus dipyridamole was clearly superior to aspirin in the ESPS-2 [45] and ESPRIT trials [46] for secondary stroke prevention. A number of meta-analyses, in particular one network meta-analysis, suggested that the combination of aspirin and dipyridamole should be superior to clopidogrel [47]. In this metaanalysis the combination of aspirin and dipyridamole was more effective than thienopyridines (odds ratio $0.84 ; 95 \%$ CI 0.73-0.97). The PRoFESS trial randomized 20,332 patients after ischemic stroke to either clopidogrel $75 \mathrm{mg}$ once daily or aspirin $25 \mathrm{mg}$ plus slow-release dipyridamole $200 \mathrm{mg}$ twice daily. After 2.15 years of follow-up, the primary end point, recurrent stroke, was the same in both treatment groups. The risk of major bleeds was higher with combination therapy. 
Lessons learned from PRoFESS:

(1) We should not base our treatment decisions on indirect comparisons with results from randomized trials

(2) In most studies in cardiology and neurology, combined antiplatelet agents result in a higher rate of major bleeds than monotherapy [48]

\section{The ACCESS Study}

Most patients who are admitted with an acute stroke have increased blood pressure. High blood pressure has a negative impact on outcome [49]. Therefore we performed a phase II safety study and planned to randomize 500 patients with acute stroke and blood pressure $>180 \mathrm{~mm} \mathrm{Hg}$ to either candesartan or placebo. The trial was terminated prematurely when 342 patients had been randomized due to a significant imbalance in end points. When the study was unblinded, it turned out that, contrary to our concerns, antihypertensive treatment was superior to placebo [50]. This resulted in a large phase III trial. SCAST recruited 2,029 patients with acute stroke and blood pressure $>140 \mathrm{~mm} \mathrm{Hg}$. Patients were either treated with candesartan or placebo for 7 days. The trial was unable to find a benefit of blood pressure lowering with candesartan in acute stroke and raised blood pressure [51].

\section{Final Conclusions}

Trial design and conduct have made tremendous progress in the last 30 years. Learning from the mistakes and failures in the past will further improve ways we design and perform treatment trials in acute stroke and stroke prevention. A shown in table 1, mistakes are not always a bad thing.

\section{Acknowledgments}

I would like to thank many colleagues and friends who planned and performed clinical trials with me: H.P. Adams; G.W. Albers, P. Amarenco, P. Bath, J. Bogousslavsky, N. Bornstein, M.G. Bousser, L.M. Brass, T. Brott, B.P.L. Chan, L. Cuhna, L. Csiba, A. Davalos, S.M. Davis, G.A. Donnan, J.D. Easton, C. Estol, M. Fisher, G.A. Ford, P. Gorelick, J. Grotta, W. Hacke, G. Hankey, M. Hennerici, M. Kaste, K.R. Lees, D. Leys, P. Leyden, R.L. Sacco, H. Schäfer, J. Schrader, A. Shuaib, J. Sivenius, D. Toni, E.J. Topol, J. Vollmar, R. Weber, C. Warlow, S. Yusuf. Everything which went wrong was my fault, everything that went well was their input. I also want to thank the highly competent partners we had in the pharmaceutical industry.

\section{Disclosure Statement}

H.-C.D. received honoraria for participation in clinical trials, contribution to advisory boards or oral presentations from: Abbott, Allergan, AstraZeneca, Bayer Vital, BMS, Boehringer Ingelheim, CoAxia, Corimmun, Covidien, Daichii-Sankyo, D-Pharm, EV3, Fresenius, GlaxoSmithKline, Janssen Cilag, Johnson \& Johnson, Knoll, MSD, Medtronic, MindFrame, Neurobiological Technologies, Novartis, Novo-Nordisk, Paion, Parke-Davis, Pfizer, Sanofi-Aventis, Schering-Plough, Servier, Solvay, Thrombogenics, Wyeth and Yamanouchi. Financial support for research projects was provided by Astra/Zeneca, GSK, Boehringer Ingelheim, Lundbeck, Novartis, Janssen-Cilag, Sanofi-Aventis, Syngis and Talecris. The Department of Neurology at the University Duisburg-Essen received research grants from the German Research Council (DFG), German Ministry of Education and Research (BMBF), European Union, NIH, Bertelsmann Foundation and Heinz-Nixdorf Foundation. H.-C.D. has no ownership interest and does not own stocks of any pharmaceutical company. Within the past year H.-C.D. served as editor of Aktuelle Neurologie, Arzneimitteltherapie, Kopfschmerznews, Stroke News and the Treatment Guidelines of the German Neurological Society, as coeditor of Cephalalgia and on the editorial board of Lancet Neurology, European Neurology and Cerebrovascular Disorders.

\section{References}

$>1$ North American Symptomatic Carotid Endarterectomy Trial Collaborators: Beneficial effect of carotid endarterectomy in symptomatic patients with high-grade carotid stenosis. N Engl J Med 1991;325:445-453.

$\checkmark 2$ European Carotid Surgery Trialists' Collaborative Group: MRC European carotid surgery trial: interim results for symptomatic patients with severe carotid stenosis and with mild carotid stenosis. Lancet 1991;337:12351243.
-3 Hennerici M, Hülsbömer H, Hefter H, Lammerts D, Rautenberg W: Natural history of asymptomatic extracranial arterial disease. Results of a long-term prospective study. Brain 1987;110:777-791.

4 The CASANOVA Study Group: Carotid surgery versus medical therapy in asymptomatic carotid stenosis. Stroke 1991;22: 1229-1235.

5 Stroke Therapy Academic Industry Roundtable (STAIR): Recommendations for standards regarding preclinical neuroprotective and restorative drug development. Stroke 1999;30:2752-2758.
6 Stroke Therapy Academic Industry Roundtable II (STAIR-II): Recommendations for clinical trial evaluation of acute stroke therapies. Stroke 2001;32:1598-1606.

7 Fisher M, Stroke Therapy Academic Industry Roundtable: Recommendations for advancing development of acute stroke therapies: Stroke Therapy Academic Industry Roundtable 3. Stroke 2003;34:1539-1546.

${ }_{8}$ Fisher M, Albers GW, Donnan GA, Furlan AJ, Grotta JC, Kidwell CS, et al: Enhancing the development and approval of acute stroke therapies: stroke therapy academic industry roundtable. Stroke 2005;36:1808-1813.
Failures, Mistakes and Shortcomings of My Stroke Trials
Cerebrovasc Dis 2013;36:250-256 DOI: $10.1159 / 000354179$ 
$\checkmark 9$ Savitz SI, Fisher M: Future of neuroprotection for acute stroke: in the aftermath of the SAINT trials. Ann Neurol 2007;61:396-402.

10 Fisher M, Feuerstein G, Howells DW, Hurn PD, Kent TA, Savitz SI, et al: Update of the stroke therapy academic industry roundtable preclinical recommendations. Stroke 2009; 40:2244-2250.

-11 Yenari MA, Bell TE, Kotake AN, Powell M, Steinberg GK: Dose escalation, safety and tolerance study of the competitive NMDA antagonist selfotel (CGS 19755) in neurosurgery patients. Clin Neuropharmacol 1998;21:2834.

12 Davis S, Albers GW, Diener HC, Lees KR, Norris J: Termination of acute stroke studies involving selfotel treatment. Lancet 1997;349: 32562.

13 DeRyck M, Keersmackers R, Duytschaever H, Claes C, Clicke G, Janssen M: Lubeluzole protects sensorimotor function and reduces infarct size in a photochemical stroke model. J Pharmacol Exp Ther 1996;35:748-758.

14 Aronowski J, Strong G, Grotta JC: Treatment of experimental foci ischemia in rats with lubeluzole. Neuropharmacology 1996;35: 689-693.

15 Buchkremer-Ratzmann I, Witte OW: Periinfarct and transhemispheric diaschisis caused by photothrombotic infarction in rat neocortex is reduced by lubeluzole but not by MK801. J Cereb Blood Flow Metab 1995;15(suppl 1):S38.

16 Lesage AS, Peeters L, Leysen JF: Lubeluzole, a novel long-term neuroprotectant, inhibits the glutamate-activated nitric oxide synthetase pathway. J Pharmacol Exp Ther 1996;279: 759-766.

- 17 Diener HC, Cortens M, Ford G, Grotta J, Hacke W, Kaste M, et al: Lubeluzole in acute ischemic stroke treatment: a double-blind study with an 8-hour inclusion window comparing a $10 \mathrm{mg}$ daily dose of lubeluzole with placebo. Stroke 2000;31:2543-2551.

18 Grotta J, for the US and Canadian Lubeluzole Ischemic Stroke Study Group: Lubeluzole treatment of acute ischemic stroke. Stroke 1997;27:2338-2346.

19 Diener HC, Wessel TC: Nitrous oxide modulator: lubeluzole. Curr Med Res Opin 2002; 18(suppl 2):s23-s26.

$\checkmark 20$ Young FB, Weir CJ, Lees KR: Comparison of the National Institutes of Health Stroke Scale with disability outcome measures in acute stroke trials. Stroke 2005;36:2187-2192.

21 Sareen D: Neuroprotective agents in acute ischemic stroke. J Assoc Physicians India 2002;50:250-258.

22 Dyker AG, Lees KR: Safety and tolerability of GV150526 (a glycine site antagonist at the Nmethyl-D-aspartate receptor) in patients with acute stroke. Stroke 1999;30:986-992.

-23 Lees KR, Lavelle JF, Cunha L, Diener HC, Sanders EA, Tack P, et al: Glycine antagonist (GV150526) in acute stroke: a multicentre, double-blind placebo-controlled phase II trial. Cerebrovasc Dis 2001;11:20-29.
24 Lees KR, Asplund K, Carolei A, Davis SM, Diener HC, Kaste M, et al: Glycine antagonist (gavestinel) in neuroprotection (GAIN international) in patients with acute stroke: a randomised controlled trial. Lancet 2000;355: 1949-1954.

25 Sacco RL, DeRosa JT, Haley EC Jr, Levin B, Ordronneau P, Phillips SJ, et al: Glycine antagonist in neuroprotection for patients with acute stroke: GAIN Americas: a randomized controlled trial. JAMA 2001;285:1719-1728.

26 Marshall JW, Cummings RM, Bowes LJ, Ridley RM, Green AR: Functional and histological evidence for the protective effect of NXY059 in a primate model of stroke when given $4 \mathrm{~h}$ after occlusion. Stroke 2003;34:22282233.

-27 Marshall JW, Duffin KJ, Green AR, Ridley RM: NXY-059, a free radical-trapping agent, substantially lessens the functional disability resulting from cerebral ischemia in a primate species. Stroke 2001;32:190-198.

28 Lees KR, Zivin JA, Ashwood T, Davalos A, Davis SM, Diener HC, et al: NXY-059 for acute ischemic stroke. N Engl J Med 2006;354: 588-600.

-29 Shuaib A, Lees K, Lyden P, Grotta J, Davalos A, Davis S, et al: NXY-059 for acute ischaemic stroke. Results of the SAINT II trial. N Engl J Med 2007;357:562-571.

- 30 The EPILOG Investigators: Platelet glycoprotein IIb/IIIa receptor blockade and low-dose heparin during percutaneous coronary revascularization. N Engl J Med 1997;336:16891696.

- 31 The CAPTURE Investigators: Randomised placebo-controlled trial of abciximab before and during coronary intervention in refractory unstable angina: the CAPTURE Study. Lancet 1997;349:1429-1435.

32 The Abciximab in Ischemic Stroke Investigators: Abciximab in acute ischemic stroke a randomized, double-blind, placebo-controlled, dose-escalation study. Stroke 2000;31: 601-609.

33 Adams HP Jr, Effron MB, Torner J, Davalos A, Frayne J, Teal P, et al: Emergency administration of abciximab for treatment of patients with acute ischemic stroke: results of an international phase III trial: Abciximab in Emergency Treatment of Stroke Trial (AbESTTII). Stroke 2008;39:87-99.

- 34 Algra A, van Gijn J: Aspirin at any dose above $30 \mathrm{mg}$ offers only modest protection after cerebral ischaemia. J Neurol Neurosurg Psychiatry 1996;60:197-199.

35 ESPS Group: European stroke prevention study. Stroke 1990;21:1122-1130.

36 Diener HC, Cunha L, Forbes C, Sivenius J, Smets P, Lowenthal A: European Stroke Prevention Study. 2. Dipyridamole and acetylsalicylic acid in the secondary prevention of stroke. J Neurol Sci 1996;143:1-13.

37 Diener HC, Darius H, Bertrand-Hardy JM, Humphreys M: Cardiac safety in the European Stroke Prevention Study 2 (ESPS2). Int J Clin Pract 2001;55:162-163.
38 Diener H, Davidai G: Dipyridamole and headache. Future Neurol 2007;2:279-283.

-39 CAPRIE Steering Committee: A randomised, blinded trial of clopidogrel versus aspirin in patients at risk of ischaemic events (CAPRIE). Lancet 1996;348:1329-1339.

40 Jones L, Griffin S, Palmer S, Main C, Orton V, Sculpher M, et al: Clinical effectiveness and cost-effectiveness of clopidogrel and modified-release dipyridamole in the secondary prevention of occlusive vascular events: a systematic review and economic evaluation. Health Technol Assess 2004;8:iii-iv, 1-196.

41 Yusuf S, Zhao F, Mehta SR, Chrolavicius S, Tognoni G, Fox KK: Effects of clopidogrel in addition to aspirin in patients with acute coronary syndromes without ST-segment elevation. N Engl J Med 2001;345:494-502.

42 Steinhubl SR, Berger PB, Mann JT 3rd, Fry ET, DeLago A, Wilmer C, et al: Early and sustained dual oral antiplatelet therapy following percutaneous coronary intervention: a randomized controlled trial. JAMA 2002;288:2411-2420.

43 Diener H, Bogousslavsky J, Brass L, Cimminiello C, Csiba L, Kaste M, et al: Acetylsalicylic acid on a background of clopidogrel in high-risk patients randomised after recent ischaemic stroke or transient ischaemic attack: the MATCH trial results. Lancet 2004; 364:331-334.

44 Benavente OR, Hart RG, McClure LA, Szychowski JM, Coffey CS, Pearce LA, et al: Effects of clopidogrel added to aspirin in patients with recent lacunar stroke. N Engl J Med 2012;367:817-825.

-45 Diener HC, Forbes C, Riekkinen PJ, Sivenius J, Smets P, Lowenthal A, et al: European Stroke Prevention Study 2: efficacy and safety data. J Neurol Sci 1997;151(suppl):S1-S77.

46 The ESPRIT Study Group: Aspirin plus dipyridamole versus aspirin alone after cerebral ischaemia of arterial origin (ESPRIT): randomised controlled trial. Lancet 2006;367: 1665-1673.

47 Thijs V, Lemmens R, Fieuws S: Network meta-analysis: simultaneous meta-analysis of common antiplatelet regimens after transient ischaemic attack or stroke. Eur Heart J 2008; 29:1086-1092.

48 Weber R, Brenck J, Diener HC: Antiplatelet therapy in cerebrovascular disorders. Handb Exp Pharmacol 2012;210:519-546.

49 Leonardi-Bee J, Bath P, Phillips S, Sandercock P, IST Collaborative Group: Blood pressure and clinical outcomes in the International Stroke Trial. Stroke 2002;33:1315-1320.

-50 Schrader J, Lüders S, Kulschewski A, Berger J, Zidek W, Treib J, et al: The ACCESS Study: evaluation of acute candesartan cilexetil therapy in stroke survivors. Stroke 2003;34:16991703.

51 Sandset EC, Bath PM, Boysen G, Jatuzis D, Korv J, Luders S, et al: The angiotensin-receptor blocker candesartan for treatment of acute stroke (SCAST): a randomised, placebo-controlled, double-blind trial. Lancet 2011;377: 741-750. 